\title{
Block copolymer selectivity: A new dry etch approach for cylindrical applications
}

\author{
Aurelien Sarrazin \\ CEA, LETI, MINATEC Campus, 17 rue des Martyrs, 38054 Grenoble Cedex 9, France and Institut des \\ matériaux Jean Rouxel (IMN), Université de Nantes-CNRS, 2 rue de la Houssinière, 44322 Nantes, France \\ Nicolas Posseme, ${ }^{\text {a) }}$ Patricia Pimenta-Barros, Sebastien Barnola, Ahmed Gharbi, \\ Maxime Argoud, and Raluca Tiron \\ CEA, LETI, MINATEC Campus, 17 rue des Martyrs, 38054 Grenoble Cedex 9, France \\ Christophe Cardinaud \\ Institut des matériaux Jean Rouxel (IMN), Université de Nantes-CNRS, 2 rue de la Houssinière, 44322 Nantes, \\ France
}

(Received 9 April 2018; accepted 26 June 2018; published 12 July 2018)

\begin{abstract}
A critical challenge for directed self-assembly of block copolymers is the selectivity between the two polymer phases. Polystyrene-block-poly(methyl methacrylate) (PS-b-PMMA) is one of the most studied block-copolymers to reach sub-20 nm patterns. A very high PMMA/PS selectivity $(>10: 1)$ is required to conserve a sufficient PS pattern thickness allowing pattern transfer to sublayers. In this paper, the authors propose to develop a chemistry allowing a full PMMA removal without PS consumption. It is based on $\mathrm{CO}$ and $\mathrm{CO}-\mathrm{H}_{2}$ cycles allowing to get a very high etch control. The proposed etch mechanisms have been understood thanks to x-ray photoelectron spectroscopy analyses performed on blanket wafers. Finally, this new etch process has been validated on the cylindrical PS- $b$-PMMA patterned structure. Published by the AVS. https://doi.org/10.1116/1.5034133
\end{abstract}

\section{INTRODUCTION}

For decades, optical lithography has been the driver of microelectronics, as the technologies' critical dimensions (CD) were directly defined by the photolithography resolution as known as the Rayleigh criterion. But for a few years, optical lithography only is not able to achieve a higher resolution and lower dimension. New patterning techniques such as multiple patterning, extreme ultraviolet lithography, direct self-assembly (DSA), and e-beam lithography are being developed to achieve future node requirements. ${ }^{1}$

DSA is one of the promising low cost solutions to reach high density sub-20 nm patterns by limiting lithography costs. The resolution of this bottom-up technique will only be limited by the material properties of the block copolymers (BCP) used. ${ }^{2-4}$

Several block-copolymers have been studied for sub$20 \mathrm{~nm}$ patterning. Polystyrene-block-poly(methyl methacrylate) (PS- $b$-PMMA) is the commonly used block-copolymer for DSA applications due to its well-known properties and its easy synthesis. ${ }^{5,6}$ Volume fractions of PS and PMMA blocks in the block-copolymer determine the pattern morphology. ${ }^{7}$ Lamellar or cylindrical PMMA patterns in a PS matrix can be created. ${ }^{8}$ According to these properties, line and contact applications could be achieved using DSA.

One of the major challenges for DSA integration concerns PMMA removal selectively to PS. Indeed, to be able to transfer patterns from the $\mathrm{BCP}$ into subjacent layers, it is important to remove PMMA without altering PS. This removal can be achieved by solvent or by plasma etching. Plasma provides better compatibility with narrow lines

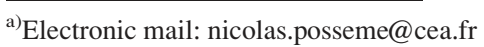

limiting the risk of pattern collapses for lamellar applications. However, one major challenge of this technique is to get high selectivity between PMMA and PS films.

PMMA removal selectivity to PS by plasma etching has widely been studied during the last decade. Different etch chemistries have been proposed in the literature to etch PMMA selectively to PS. ${ }^{9}$ Two plasma etch approaches have been evaluated as the most promising ones: a $\mathrm{CO}-\mathrm{H}_{2}$ chemistry developed in the meantime by Toshiba Corporation ${ }^{10}$ and by CEA-LETI ${ }^{11}$ and a succession of $\mathrm{Ar}$ and $\mathrm{Ar}-\mathrm{O}_{2}$ cycles proposed by IMEC. ${ }^{12}$

In this paper, we propose to study $\mathrm{CO}$ and $\mathrm{CO}-\mathrm{H}_{2}$ cycles as a solution to remove PMMA selectively to PS. This process has been developed on $300 \mathrm{~mm}$ blanket homopolymer wafers. Complementary $\mathrm{x}$-ray photoelectron spectroscopy (XPS) analyses have been performed to understand the etch mechanisms. Finally, this new etch process has been validated on cylindrical patterned PS- $b$-PMMA copolymer structures.

\section{EXPERIMENT}

\section{A. Materials}

PS and PMMA homopolymer solutions, provided by Arkema $^{\circledR}$, were spin-coated on $300 \mathrm{~mm}$ blanket wafers and then annealed on Sokudo Duo ${ }^{\mathrm{TM}}$ track to obtain films with a thickness of $50 \mathrm{~nm}$.

Figures 1(a) and 1(b) show PS and PMMA formulae, ${ }^{13}$ respectively.

PS is a polymer composed of an aliphatic carbon and hydrogen backbone chain with a phenyl group (aromatic $-\mathrm{C}_{6} \mathrm{H}_{5}$ ) replacing a hydrogen atom every two $\mathrm{CH}_{2}$ as shown in Fig. 1(a). While PMMA, which is also based on an aliphatic 
backbone chain, presents methyl $\left(-\mathrm{CH}_{3}\right)$ and methacrylate $\left(-\mathrm{COOCH}_{3}\right)$ groups substituted to the hydrogen atoms every two $\mathrm{CH}_{2}$ as shown in Fig. 1(b).

PS- $b$-PMMA is a block-copolymer (BCP) composed of PS and PMMA chains. These polymer chains are arranged by block, it means that a chain of several monomers from one polymer will be linked to a chain of monomers from the second polymer. The intrinsic period of the studied polymer, provided by Arkema under the tradename Nanostrength ${ }^{\circledR}$ $\mathrm{EO}$, is $\mathrm{L}_{0}=35 \mathrm{~nm}$, and the PMMA/PS volume fraction is $30 / 70$ $\left(\mathrm{Mn}_{\mathrm{PMMA}}=18.5 \mathrm{~kg} / \mathrm{mol}\right.$ and $\left.\mathrm{Mn}_{\mathrm{PS}}=38.6 \mathrm{~kg} / \mathrm{mol}\right)$ in order to get a cylindrical morphology dedicated to contact patterning applications. Then, BCP is dissolved in propylene glycol monomethyl ether acetate solvent, and the solution is further coated and annealed on $300 \mathrm{~mm}$ wafers using Sokudo Duo track to get a film around $40 \mathrm{~nm}$.

Our application requires that the patterns (PMMA cylinders in our case) are self-assembled themselves perpendicularly to the substrate. Therefore, a thin neutral layer should be added under the BCP film. ${ }^{14}$ This layer is a grafted PS$r$-PMMA random copolymer, meaning that PS and PMMA monomers are randomly distributed in the copolymer. In the following, this layer is called brush. The brush and BCP layer thicknesses are around 8 and $42 \mathrm{~nm}$, respectively.

Complementary information about the investigated materials can be found in a previous paper. ${ }^{15}$

\section{B. Etching setup}

Plasma etching has been carried out on a $300 \mathrm{~mm}$ Flex ${ }^{\circledR}$ reactor from LamResearch ${ }^{\circledR}$. This capacitive coupled plasma reactor generates two frequencies $(2$ and $27 \mathrm{MHz}$ ) on the bottom electrode. An $\mathrm{O}_{2}$-based waferless auto clean is performed before and after each wafer.

The investigated etch process is composed of two steps: a $\mathrm{CO}$ step followed by $\mathrm{CO}-\mathrm{H}_{2}$ step (process conditions are

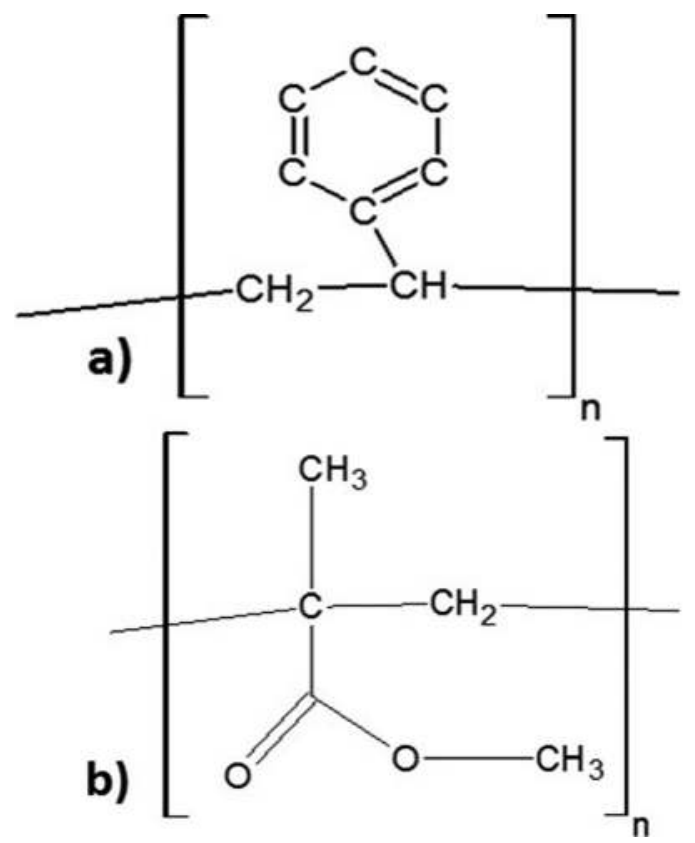

FIG. 1. PS (a) and PMMA (b) semideveloped chemical formulas. detailed in Table I). The best $\mathrm{CO}-\mathrm{H}_{2}$ gas ratio has already been set in a previous paper to $1: 1 .^{15}$

\section{Characterization setup}

The thickness measurement used to determine etch selectivity has been obtained by ellipsometry made before and after plasma etching of PS and PMMA homopolymers with an ALERIS HX ${ }^{\mathrm{TM}}$ setup from KLA TENCOR ${ }^{\mathrm{TM}}$ for an incident angle of $71^{\circ}$. A Cauchy transparent model has been used for the thickness measurement from the wavelength between 400 and $850 \mathrm{~nm}$ for both materials. To take into account the polymer modification induced by plasma, the medium refractive index is also adjusted in the model during the thickness fitting. Pristine PS has a real index of 1.49 while PMMA has an index of 1.59 at $620 \mathrm{~nm}$; these materials exhibit no absorption $(\kappa=0)$ in this wavelength range. For the etching regime, no index modification has been observed. Concerning polymer surface phenomena, the refractive medium index cannot be significantly different and the modified layer thickness is limited, it does not allow a model with two different layers. Pristine PS or PMMA homopolymer film thicknesses have been evaluated at $50 \mathrm{~nm}$ with these ellipsometric considerations.

Surface etching mechanism phenomena have been understood, thanks to ex situ XPS experiments. These have been carried out on a Thermo Fisher Scientific Theta 300 spectrometer operating with a monochromatic $\mathrm{Al} \mathrm{K} \alpha$ x-ray source $(h \nu=1486.6 \mathrm{eV})$. The concentrations of $\mathrm{C}$ and $\mathrm{O}$ atoms are extracted from the $\mathrm{C} 1 s$ and $\mathrm{O} 1 s$ core-level energy regions, respectively.

Spectral fitting is performed to extract the various peaks contribution in the acquired energy regions. Individual line shapes are decomposed with a combination of Lorentzian and Gaussian functions. Each element concentration can be obtained by dividing the calculated peak areas by the corresponding Scofield cross section (O1s: 2.93; C1s: 1.0). The sum of the concentrations for the different elements on the analyzed surfaces is equal to $100 \%$.

XPS measurements have been carried out for ten scans with a dwell time of $500 \mathrm{~ms}$ and a pass energy of $50 \mathrm{eV}$, giving a spectral resolution of $1 \mathrm{eV}$. The analyzed surfaces are measured at $23.75^{\circ}$ take off angle from the normal incidence.

In order to compare the impact of the different plasma chemistries on PS and PMMA, experiments have been carried out at the same time for the different chemistries for each material. Small samples $\left(5 \times 5 \mathrm{~cm}^{2}\right)$ have been set on the same $300 \mathrm{~mm}$ silicon wafer, with kapton backside, to be characterized without turning the $\mathrm{x}$-ray gun off. The distance between the gun and the different samples is constant.

TABLE I. Main gas parameter description.

\begin{tabular}{lccc}
\hline Gas & Pressure & Bias power $(2 \mathrm{MHz})$ & Source power $(27 \mathrm{MHz})$ \\
\hline Step 1: CO & 120 mTorr & $50 \mathrm{~W}$ & $150 \mathrm{~W}$ \\
Step 2: $\mathrm{CO}-\mathrm{H}_{2}$ & 120 mTorr & $50 \mathrm{~W}$ & $150 \mathrm{~W}$ \\
\hline \hline
\end{tabular}


Scanning electron microscopy (SEM) has been used for morphological observations, and a critical dimension scanning electron microscopy Hitachi CG4000 ${ }^{\mathrm{TM}}$ for the determination of the pattern shape and dimension. SEM images have been acquired with an accelerating voltage of $500 \mathrm{~V}$ and a probe current of $6 \mathrm{pA}$. Based on SEM images, PMMA cylinder dimensions have been determined by a Matlab ${ }^{\mathrm{TM}}$ script based on gray-level image thresholding. ${ }^{16}$ The critical dimensions (CD) of 500 cylinders have been determined for each plasma condition. However, the dimensions extracted from this $\mathrm{Matlab}^{\mathrm{TM}}$ script are only estimated values as the values are dependent on the threshold parameter. The same threshold parameter has been used for all image treatment in this paper to allow an efficient comparison between the different etching conditions.

Cross section has been carried out to determine the effectiveness of PMMA removal with a Hitachi S5000 ${ }^{\mathrm{TM}}$. Crosssectional samples have been obtained after a gold-palladium metallization of $25 \mathrm{~s}$ to reduce charging effect characteristic of the polymer reaction to electron beam. All the cross sections have been observed at a $350000 \times$ magnification, for an accelerating voltage of $30 \mathrm{keV}$ and a probe current of $10 \mu \mathrm{A}$. To determine the PMMA efficiency on cylindrical patterns, $20^{\circ}$-titled images have been observed.

\section{RESULTS AND DISCUSSION}

\section{A. PMMA removal selectively to PS on blanket wafers \\ 1. Choice of $\mathrm{CO}$ and $\mathrm{CO}: \mathrm{H}_{2}$ step time}

Figure 2 summarizes polystyrene and PMMA consumption as a function of plasma process time for $\mathrm{CO}$ and $\mathrm{CO}-\mathrm{H}_{2}$ etch chemistries.

Using CO chemistry, no PS consumption is observed during the first seconds of plasma while a $3 \mathrm{~nm}$ material deposition is measured on top of PS after $200 \mathrm{~s}$ without the refractive medium index evolution. In the meantime, $20 \mathrm{~nm}$ PMMA is consumed during the first $20 \mathrm{~s}$. Beyond this time, the PMMA is not etched anymore.

For $\mathrm{CO}-\mathrm{H}_{2}$ chemistry, the PMMA consumption is linear between 10 and $100 \mathrm{~s}$, with an etch rate estimated to be $15 \mathrm{~nm} / \mathrm{min}$. In the meantime, the PS consumption is estimated to be $3 \mathrm{~nm}$ for a process time between $10 \mathrm{~s}$ and $30 \mathrm{~s}$ and reaches a plateau $(4 \mathrm{~nm})$ beyond this time.

Based on these trends, we have proposed to cycle alternatively $\mathrm{CO}$ and $\mathrm{CO}-\mathrm{H}_{2}$ steps. The first step of $\mathrm{CO}$ is etching PMMA while depositing on PS. Then, the $\mathrm{CO}-\mathrm{H}_{2}$ step partially removes the deposition on PS while etching the PMMA. A trade-off has to be found for $\mathrm{CO}$ and $\mathrm{CO}-\mathrm{H}_{2}$ process times to avoid the etch stop phenomenon or PS consumption.

Therefore, in our experimental conditions, the process times for $\mathrm{CO}$ and $\mathrm{CO}-\mathrm{H}_{2}$ process steps have been set at $15 \mathrm{~s}$ and $25 \mathrm{~s}$, respectively.

\section{Effect of the number of cycles on PS and PMMA consumption}

In Fig. 3, PMMA and PS consumptions are plotted as a function of cycle chemistry evolution. First, we have
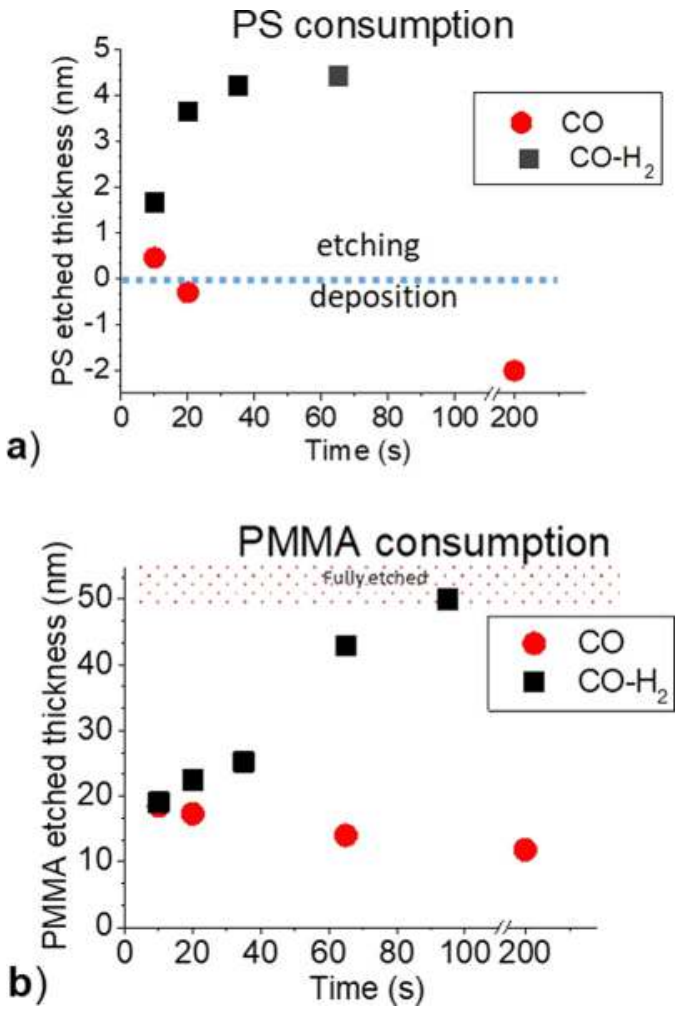

FIG. 2. (Color online) Polymer consumption to $\mathrm{CO}$ and $\mathrm{CO}-\mathrm{H}_{2}$ plasma on PS (a) and PMMA (b).

confirmed effects of CO 15 s on PS and PMMA: no PS etching is observed while a $15 \mathrm{~nm}$ PMMA removal is measured.

After 1 cycle (CO $15 \mathrm{~s}+\mathrm{CO}-\mathrm{H}_{2} 25 \mathrm{~s}$ ), PMMA consumption is about $20 \mathrm{~nm}$ while no PS film thickness has been consumed. After 2 cycles, the PMMA film is still etched while PS remains not etched. By increasing the number of cycles (not shown here), PMMA consumption reaches a plateau, explained by a nonoptimized $\mathrm{CO}+\mathrm{CO}-\mathrm{H}_{2}$ step time. This phenomenon can be overcome with a better control of the deposit thickness or etching rate which could be controlled by the process times.

We demonstrated that PMMA can be removed without PS consumption by cycling $\mathrm{CO}$ and $\mathrm{CO}-\mathrm{H}_{2}$ chemistries. These results are very close to those obtained by Miyazoe et al. without removing $\mathrm{H}_{2}$ flow on the first step. ${ }^{17}$

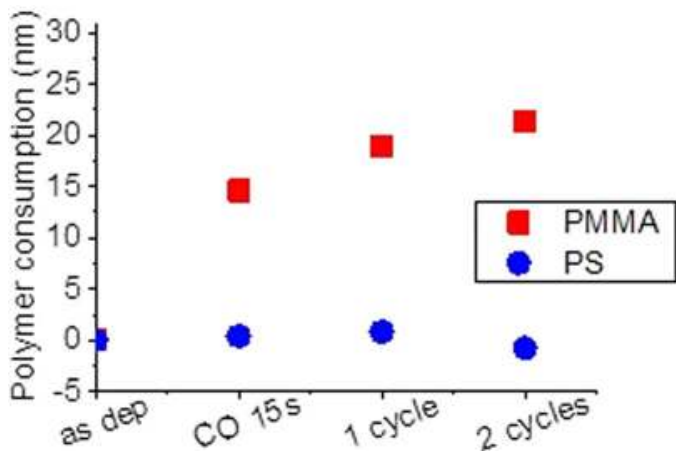

FIg. 3. (Color online) Example of interest of cycling $\mathrm{CO}$ and $\mathrm{CO}-\mathrm{H}_{2}$ steps for removing PMMA selectively to PS. 
In the following part, we have investigated PS and PMMA surface evolution as a function of $\mathrm{CO}$ and $\mathrm{CO}-\mathrm{H}_{2}$ cycle number.

\section{B. Plasma-material interaction understanding}

In order to understand differences in the plasma-materials interaction mechanisms allowing to etch PMMA without PS consumption, XPS experiments have been carried out. According to these analyses, we have determined the surface film composition for the chemistries based on cycling $\mathrm{CO}$ and $\mathrm{CO}-\mathrm{H}_{2}$ steps.

To have a better understanding, we have compared XPS analysis obtained for the cycling chemistry with results obtained for $\mathrm{CO}$ and $\mathrm{CO}-\mathrm{H}_{2}$ chemistry which have been previously presented in detail. ${ }^{15} \mathrm{PS}$ and PMMA surface compositions for $\mathrm{CO}$ and $\mathrm{CO}-\mathrm{H}_{2}$ processes have been plotted in Fig. 4.

This XPS analysis has been carried out to characterize the film surface composition evolution. For CO plasma on PS and PMMA films, we can observe an increase in carbonoxide bonds concentration by increasing the process time [Figs. 4(a) and 4(b)]. On PS, we can observe that carbonoxide bonds represent around $15 \%$ after $10 \mathrm{~s}$ and $40 \%$ after $200 \mathrm{~s}$. There is an oxygen increase from the first seconds of the process. On PMMA, we have an oxygen amount decrease on first process seconds. Then, a carbon-oxide bond density stagnation at around $30 \%$ is observed until $65 \mathrm{~s}$. Finally, this bond density is slightly increasing after $200 \mathrm{~s}$. Thus, similarities can be observed between both polymers with an increase in carbon-oxide bonds concentration with $\mathrm{CO}$ process time. By comparing these results to ellipsometry, we can conclude that carbon-oxide material is deposited on top of both polymers. This deposit induces a PMMA etching saturation phenomenon after 20 s process time while the PS is not etched at all.

For $\mathrm{CO}-\mathrm{H}_{2}$, there is no significant modification between spectra after 20 and 65 s process times [Figs. 4(c) and 4(d)]. However, we can detect a slight oxygen composition increase in PS between 20 and $65 \mathrm{~s}$ while there is almost no modification on PMMA. In both cases, it can be deduced that we are at an etch steady state regime. This etching regime with $\mathrm{CO}-\mathrm{H}_{2}$ is confirmed by ellipsometry measurements.

According to ellipsometry and XPS analyses, we can confirm that a deposit is created on both polymers with $\mathrm{CO}$ chemistry. Therefore, CO chemistry does not allow a full PMMA removal. While for $\mathrm{CO}-\mathrm{H}_{2}$, PS and PMMA are etched. These mechanisms have been deeply detailed in the previous paper. ${ }^{15}$

The evolution of PS and PMMA surface compositions during $\mathrm{CO}$ and $\mathrm{CO}-\mathrm{H}_{2}$ cycling chemistry has been plotted in Fig. 5.

By cycling $\mathrm{CO}(15 \mathrm{~s})$ and $\mathrm{CO}-\mathrm{H}_{2}(25 \mathrm{~s})$ steps, no significant modification can be observed on the PS or PMMA surface compositions compared to $\mathrm{CO}$ only. On PS, the composition does not evolve from the first $\mathrm{CO}$ step to the end of the second cycle, we could consider that the deposit is not evolving as a function of the cycle numbers. For PMMA,

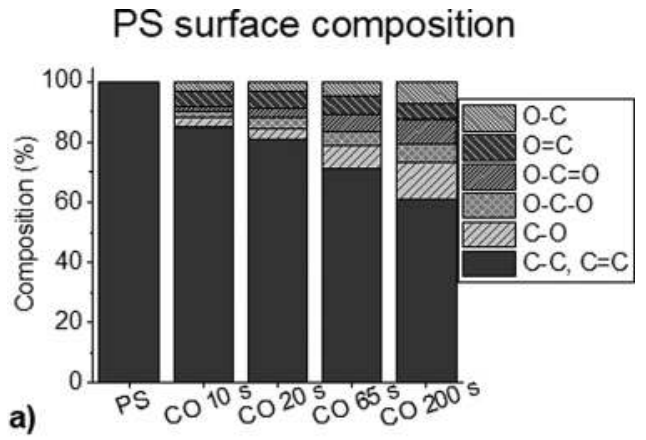

PMMA surface composition

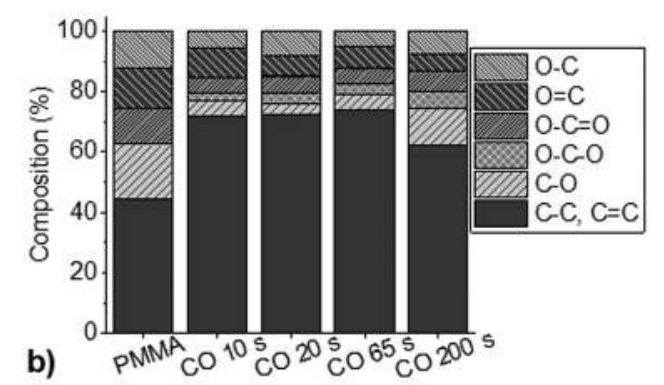

PS surface composition

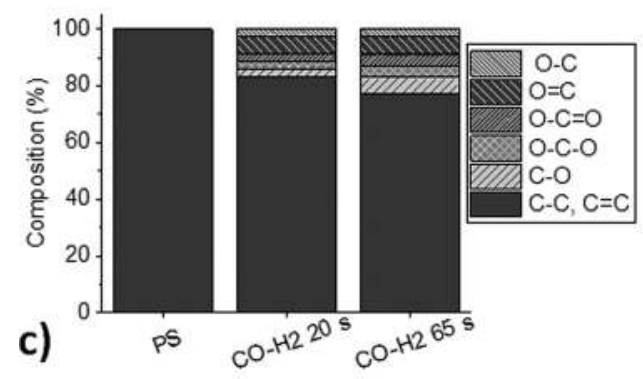

PMMA surface composition

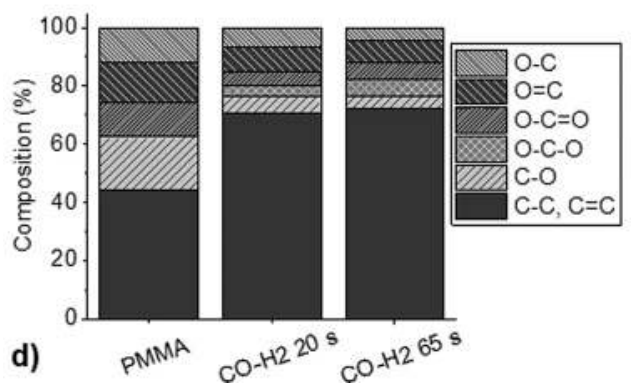

FIG. 4. XPS analysis of PS [(a) and (c)] and PMMA [(b) and (d)] surface compositions for $\mathrm{CO}\left[(\mathrm{a})\right.$ and (b)] and $\mathrm{CO}-\mathrm{H}_{2}$ plasma $[(\mathrm{c})$ and (d)].

the $\mathrm{C}-\mathrm{O}$ bond density seems to be slightly reduced with the process evolution after a significant oxygen loss induced by PMMA etching of the first seconds. However, ex situ XPS experiment cannot allow a precise characterization of the surface composition and to determine the real impact of chemistry on PS and PMMA. Moreover, we can consider that our process has not been optimized for allowing a PMMA removal without saturation. Finally, we can confirm the ability to remove PMMA without consuming PS with well-defined parameters. 
PS surface composition

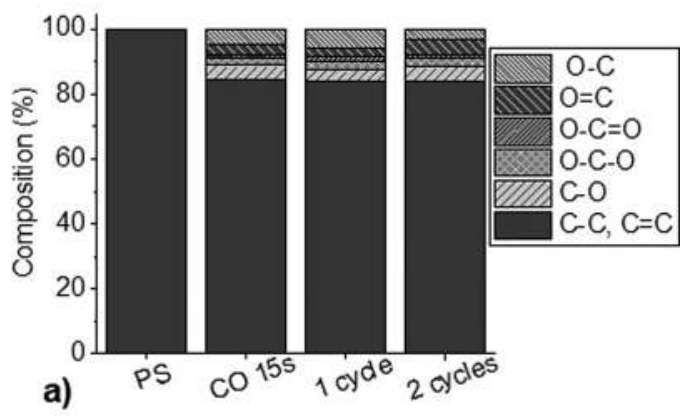

PMMA surface composition

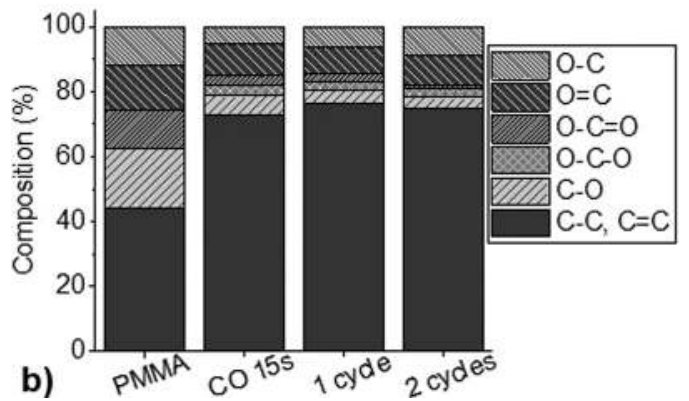

FIG. 5. XPS surface composition evolution of PS (a) and PMMA (b) films with cycles.

A perfect control of each step parameter should allow a full PMMA removal without PS consumption by cycling $\mathrm{CO}$ and $\mathrm{CO}-\mathrm{H}_{2}$ steps as schematized in Fig. 6.

On polystyrene, a thin carbon-oxide deposit is created with CO chemistry while a partial etch can be achieved on PMMA. The CO step time has to be optimized to avoid a PMMA etch stop phenomenon. Then, a $\mathrm{CO}-\mathrm{H}_{2}$ step is performed to consume PMMA material with an efficient etch rate. It could consume few angstroms of carbon-oxide deposit at the top of PS while the PMMA is etched more favorably. The control of this step allows not to etch more than the deposit at the top of PS. Then, a new CO step is performed to protect again PS and to help PMMA etching. Thus, a $\mathrm{CO}-\mathrm{H}_{2}$ step etching PMMA is used to allow a full PMMA removal. Depending on the etch rate and the thickness to etch, several cycles should be necessary. Finally, the PMMA film could be etched without consuming PS.
We have just proved that $\mathrm{CO}$ and $\mathrm{CO}-\mathrm{H}_{2}$ step combination with the plasma parameter adjustments allows to etch PMMA without consuming PS.

The validation of the new etch process to remove PMMA selectively to PS on patterned PS- $b$-PMMA with a cylindrical morphology structures is presented in Sec. III C.

\section{Application to PS- $b$-PMMA films with a cylindrical morphology}

The chemistry based on $\mathrm{CO} / \mathrm{CO}-\mathrm{H}_{2}$ cycles has been evaluated on the PS- $b$-PMMA film with a cylindrical morphology.

In Fig. 7, patterns after self-assembly without PMMA removal have been represented in top view and cross sectional SEM images.

PS- $b$-PMMA films with a cylindrical morphology has been observed after the self-assembly. Cylinder dimensions have been estimated by image threshold to $12 \mathrm{~nm}$ [Fig. 7(a)]. Cross section observation allows to determine the film thickness. The $20^{\circ}$-titled SEM image in Fig. 7(b) shows a film thickness of around $44 \mathrm{~nm}$ after BCP self-assembly. In the following, all cross section observations have been obtained with similar SEM conditions. To help the PMMA removal efficiency observation, a dotted line has been added to show the PMMA (and brush) thickness remaining and a continuous line for the underlayer interface.

First, $\mathrm{CO}$ and $\mathrm{CO}-\mathrm{H}_{2}$ steps have been evaluated separately on PS- $b$-PMMA with a cylindrical morphology in Fig. 8.

Figure 8 represents the impact of $\mathrm{CO}$ [Figs. 8(a) and 8(c)] and $\mathrm{CO}-\mathrm{H}_{2}$ steps [Figs. 8(b) and 8(d)] on the PS- $b$-PMMA film with a cylindrical morphology. The top view SEM image of the BCP film after CO plasma shows a $12 \mathrm{~nm}-\mathrm{CD}$ while a slight CD increase to $13 \mathrm{~nm}$ is observed when using $\mathrm{CO}-\mathrm{H}_{2}$ chemistry [Fig. 8(a)]. This result is in good agreement with a previous study showing an increase in the $\mathrm{CD}$ after $\mathrm{CO}-\mathrm{H}_{2}$ chemistry as a function of the process time. ${ }^{15}$ In the meantime, these cross-section views confirm a low PMMA consumption and no PS etch with the 15 s-CO step as already observed on blanket wafers, while $30 \mathrm{~nm}$ of PMMA and $10 \mathrm{~nm}$ of PS are removed with the $25 \mathrm{~s}-\mathrm{CO}-\mathrm{H}_{2}$ step.

Then, the effect of $\mathrm{CO}(15 \mathrm{~s})+\mathrm{CO}-\mathrm{H}_{2}(25 \mathrm{~s})$ chemistry on PS- $b$-PMMA is shown in Fig. 9.

After a cycle, $25 \mathrm{~nm}$ of the PMMA cylinder are removed with only $3 \mathrm{~nm}$-PS consumption. Critical dimensions are kept constant at $12 \mathrm{~nm}$.

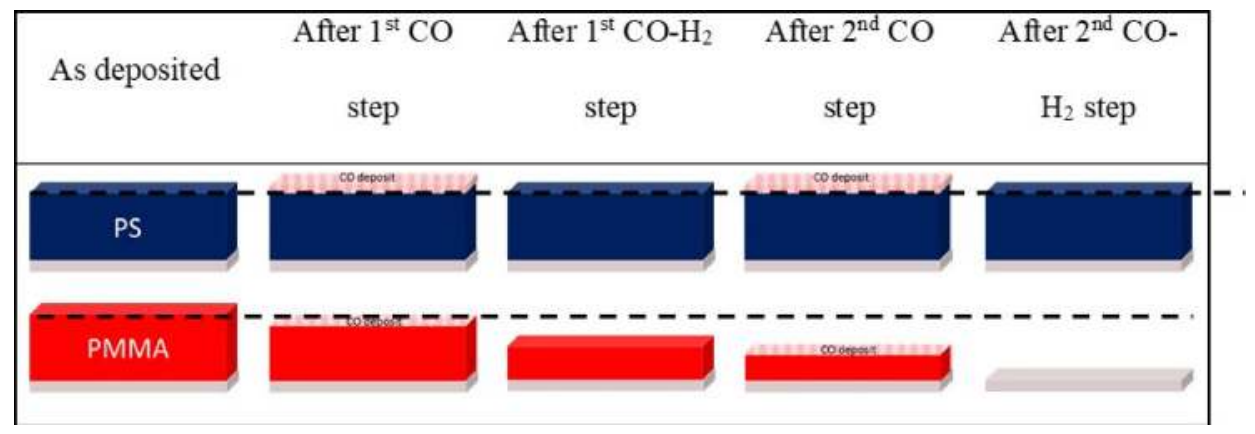

FIg. 6. (Color online) Principle of cycling $\mathrm{CO}$ and $\mathrm{CO}-\mathrm{H}_{2}$ steps to fully remove PMMA selectively to PS. 

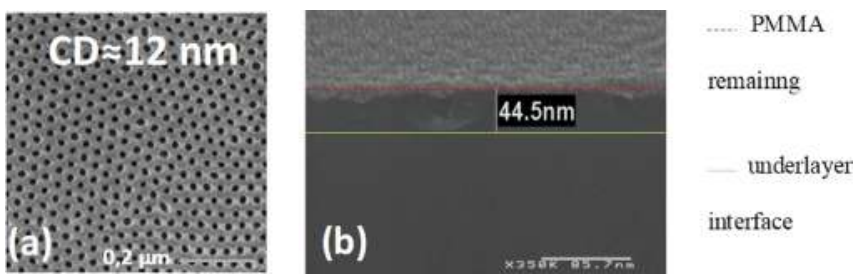

FIG. 7. (Color online) Self-organization of PS- $b$-PMMA. SEM top view (a) and cross-section (b) images.

The PMMA consumption thickness is adjusted as a function of the number of cycles as shown in Fig. 10. By increasing the cycle number, PMMA consumption is enhanced without impacting PS.

After $5 \mathrm{CO}+\mathrm{CO}-\mathrm{H}_{2}$ cycles, PMMA patterns as well as the brush layer are fully etched. Furthermore, increasing the number of cycles does not increase the CD showing the process robustness. High overetch will allow to fully remove PMMA/brush layers without widening dimensions.

In our experimental conditions, a $2 \mathrm{~nm}-\mathrm{CD}$ bias has been estimated [see Figs. 10(a)-10(e)].

These results show that cycling $\mathrm{CO}$ and $\mathrm{CO}-\mathrm{H}_{2}$ allows a full PMMA removal and inducing a CD bias of $2 \mathrm{~nm}$. However, dimensions have been determined by image threshold and contrast which has a high impact on the pattern measurement and which could be impacted by topography patterns. It means that it is not easy to compare dimensions determined after self-assembly and dimensions after PMMA removal. However, it seems that the PMMA removal by cycling $\mathrm{CO}$ and $\mathrm{CO}-\mathrm{H}_{2}$ steps does not induce a lack of pattern control because measured dimensions are the same after 3 and 5 cycles.

Finally, to be sure that the developed PMMA removal chemistry allows to be used in an integration with PS- $b$-PMMA films
$\mathrm{CO} 15 \mathrm{~s}$
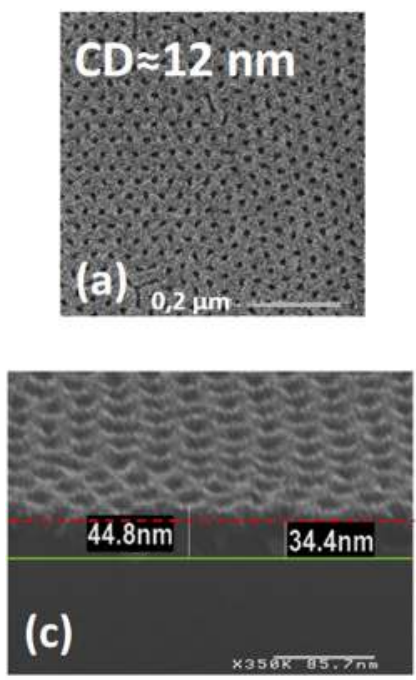

$\mathrm{CO}-\mathrm{H}_{2} 25 \mathrm{~s}$
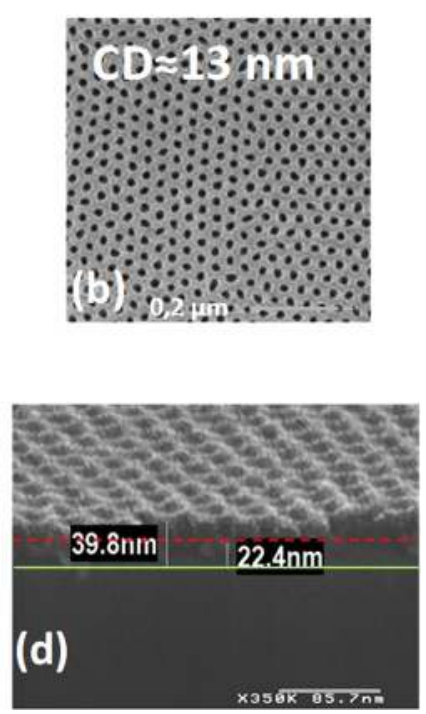

FIG. 8. (Color online) SEM top-view [(a) and (b)] and cross sectional [(c) and (d)] images of PMMA removal on the PS- $b$-PMMA film with a cylindrical morphology after CO $15 \mathrm{~s}$ [(a) and (c)] or CO- $\mathrm{H}_{2} 25 \mathrm{~s}$ [(b) and (d)] etching chemistry.
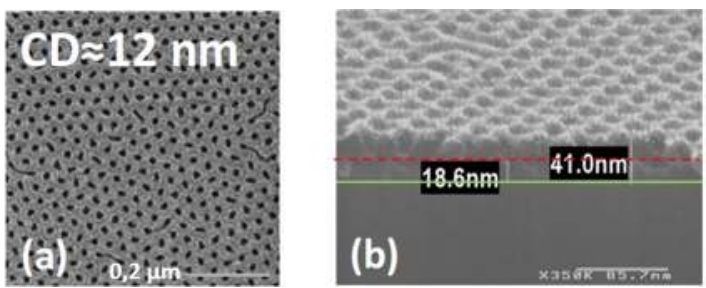

FIG. 9. (Color online) PMMA removal on the PS- $b$-PMMA film with one $\mathrm{CO}+\mathrm{CO}-\mathrm{H}_{2}$ cycle.

with a cylindrical morphology, transfer into sublayers has been investigated. Patterns have been transferred into a 30$\mathrm{nm}$ silicon-containing antireflective coating (SiARC) layer and into a 70-nm amorphous carbon [spin on carbon (SOC)] film with chemistries $\mathrm{CF}_{4} / \mathrm{Ar} / \mathrm{H}_{2}$ and $\mathrm{H}_{2} / \mathrm{N}_{2}$, respectively. ${ }^{18}$

Transfer results are presented in Fig. 11.

On the cross section after PMMA removal [Fig. 11(b)], we can easily determine the three layers (BCP, SiARC, and SOC). Thanks to this contrast, we can observe that $\mathrm{CO}+\mathrm{CO}-\mathrm{H}_{2}$ chemistry allows a full PMMA removal and that this chemistry is selective to SiARC. The top-view image associated with this PMMA removal proves that there is no behavior step difference on the SiARC underlayer compared to the $\mathrm{Si}$ substrate: a cylinder $\mathrm{CD}$ of $14 \mathrm{~nm}$. Then, transfers into SiARC-SOC layers with this developed chemistry have been proved in Fig. 11(d). This confirms the efficiency of full PMMA removal.

\section{CONCLUSION}

In this paper, we have studied PMMA removal selectively to PS on PS- $b$-PMMA films with a cylindrical morphology.

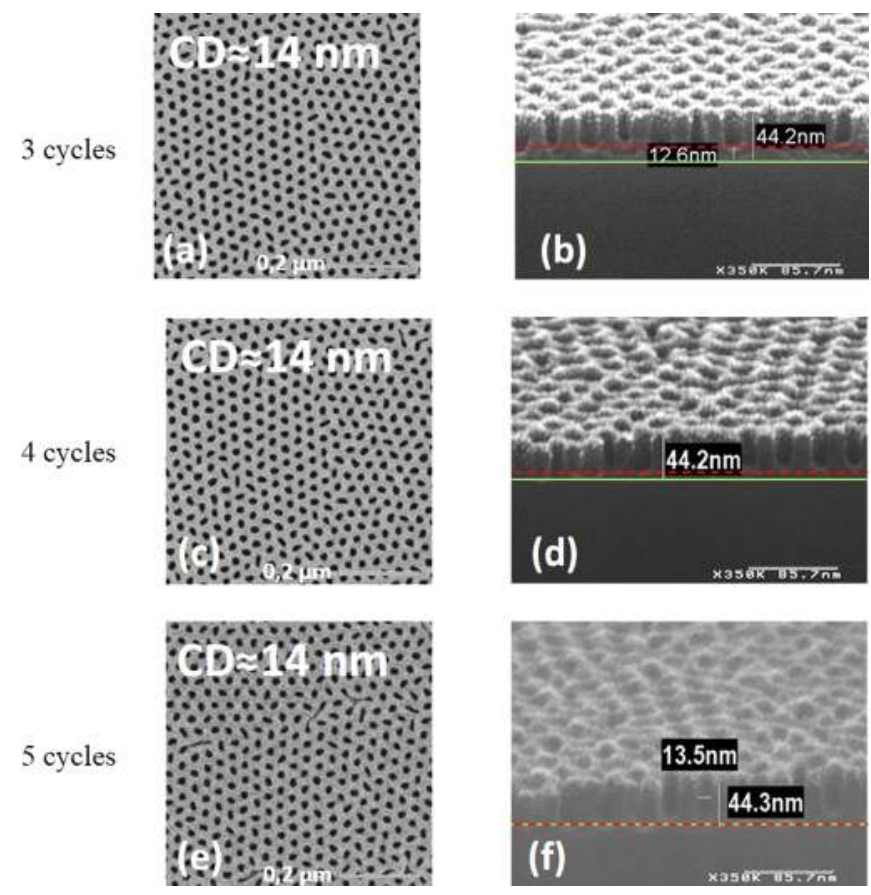

FIG. 10. (Color online) PMMA removal on the PS- $b$-PMMA film with CO/ $\mathrm{CO}-\mathrm{H}_{2}$ cycles. three cycles [(a) and (b)], four cycles [(c) and (d)], and 5 cycles [(e) and (f)]. 


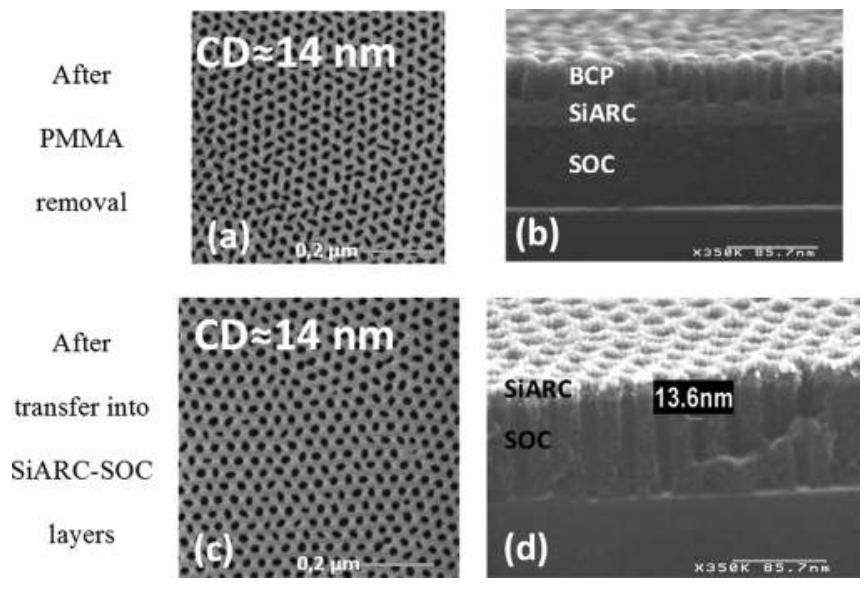

FIG. 11. PMMA removal on PS- $b$-PMMA after $5 \mathrm{CO} / \mathrm{CO}-\mathrm{H}_{2}$ cycles $[(a)$ and (b)] and after transfer into SiARC-SOC layers [(c) and (d)].

Previously, we have proved the interest of CO- $\mathrm{H}_{2}$ chemistry for this application even though selectivity was lower compared to the blanket study on homopolymers and inducing a significant $\mathrm{CD}$ bias. By developing a new chemistry based on cycling $\mathrm{CO}$ and $\mathrm{CO}-\mathrm{H}_{2}$ steps, we succeeded in etching PMMA without consuming PS on blanket wafers. This selectivity is based on the polymerization rate control from etching gases for these polymers. XPS measurements have been carried out in order to propose mechanisms of this very high selectivity. This chemistry has been applied to PS- $b$-PMMA films with a cylindrical morphology. Results have proven interest of $\mathrm{CO}+\mathrm{CO}-\mathrm{H}_{2}$ plasma cycles for this application because it allows a full PMMA removal and a brush etching without consuming PS. In the meantime, $\mathrm{CD}$ bias induced by this removal is limited (to only $2 \mathrm{~nm}$ ). Finally, to validate PMMA removal efficiency, transfers into SiARC-SOC sublayers have been investigated. These transfers have been successfully achieved conserving shape and dimensions of cylinder holes. Results for PMMA removal by plasma etching with this chemistry are as good as those obtained for UV exposure and wet development. ${ }^{19}$ We confirm that PMMA removal selectively to PS by plasma etching should be seriously considered as it allows to remove PMMA in the chamber used for the following transfer with similar results.

\footnotetext{
${ }^{1}$ N. Posseme, Plasma Etching Process for CMOS Devices Realization (Elsevier, Amsterdam, 2017).

${ }^{2}$ S. Barnola et al., Proc. SPIE 9054, 90540E (2014).

${ }^{3}$ M. P. Stoykovich and P. F. Nealey, Mater. Today 9, 20 (2006).

${ }^{4}$ R. R. Dammel, J. Photopolym. Sci. Technol. 24, 33 (2011).

${ }^{5}$ R. Tiron et al., Proc. SPIE 8323, 832300 (2012).

${ }^{6}$ X. Chevalier et al., Proc. SPIE 8680, 868006 (2013).

${ }^{7}$ I. W. Hamley, Developments in Block Copolymer Science and Technology (Wiley, NJ, 2004).

${ }^{8}$ R. A. Segalman, Mater. Sci. Eng., R 48, 191 (2005).

${ }^{9}$ S. Sirard et al., Proc. SPIE 9782, 97820K (2016).

${ }^{10}$ T. Imamura, H. Yamamoto, M. Omura, I. Sakai, and H. Hayashi, J. Vac. Sci. Technol., B 33, 61601 (2015).

${ }^{11}$ A. Sarrazin, N. Posseme, P. Pimenta Barros, and S. Barnola, "Method for selective etching of a block copolymer," FR patent 042,312 (1 March 2017).

${ }^{12}$ B. T. Chan and S. Tahara, "Etching method using block-copolymers," U.S. patent 0,131,839 (15 May 2013).

${ }^{13}$ J. E. Mark, Physical Properties of Polymers Handbook, 2nd ed. (Springer, New York, 2006).

${ }^{14}$ P. Mansky, Y. Liu, E. Huang, T. P. Russell, and C. Hawker, Science 275, 1458 (1997).

${ }^{15}$ A. Sarrazin et al., Proc. SPIE 9782, $97820 \mathrm{G}$ (2016).

${ }^{16} \mathrm{M}$. Argoud et al., Proc. SPIE 9049, 904929 (2014).

${ }^{17}$ H. Miyazoe, A. V. Jagtiani, H.-Y. Tsai, S. U. Engelmann, and E. A. Joseph, J. Phys. Appl. Phys. 50, 204001 (2017).

${ }^{18}$ I. Servin et al., Jpn. J. Appl. Phys., Part 1 53, 06JC05 (2014).

${ }^{19}$ A. Gharbi, R. Tiron, P. Pimenta Barros, M. Argoud, I. Servin, X. Chevalier, C. Nicolet, and C. Navarro, J. Vac. Sci. Technol., B 33, 51602
} (2015). 